\title{
ЦИФРОВЫЕ ТЕХНОЛОГИИ В РАЗВИТИИ НАРОДНОГО ХОЗЯЙСТВА И ГОСУДАРСТВЕННОЙ СЛУЖБЫ
}

\author{
Турлуев Ризван Рамзанович \\ старший преподаватель
}

Чеченский Государственный университет

\begin{abstract}
Аннотация: Быстрое развитие информационной экономики в настоящее время связано с внедрением сквозных цифровых технологий и формированием цифровой экономики, соответственно. Модернизация традиционных производств и сферы услуг, организация торговых и закупочных процедур, связанных с ними финансовых и логистических операций, изменение моделей потребления на фоне проникновения информационных технологий и оцифровки экономических процессов создает основу для формирования новых рынков и новые условия, а также новые подходы к аналитике, прогнозированию и принятию управленческих решений. Поэтому целью исследования является изучение российского и зарубежного опыта в условиях бурного развития цифровой экономики. Методы. Исследование проводилось с использованием общепринятых экономических методов, основанных на логическом описании компонентов и функций цифровых технологий, отражающих их существенные свойства, с использованием системного подхода, обеспечивающего необходимую глубину изучения научной проблемы. В статье рассматриваются современные тенденции трансформации системы государственного управления в контексте нарастающих глобальных вызовов развития цифровых технологий. На основе анализа международного и российского опыта внедрения цифровых технологий и платформенных решений в области государственного управления дается содержательное описание целей и задач создания «электронного правительства». Исследуются институциональная база формирования «электронного правительства» и показатели, оценивающие уровень и качество его функционирования.
\end{abstract}

Ключевые слова: Цифровые технологии, народное хозяйство, экономика, государственная служба. 


\title{
ЦИФРОВИЗАЦИЯ: РОССИЯ И СНГ В КОНТЕКСТЕ ГЛОБАЛЬНОЙ ТРАНСФОРМАЦИИ
}

\begin{abstract}
The rapid development of the information economy is currently associated with the introduction of cross-cutting digital technologies and the formation of the digital economy, respectively. Modernization of traditional industries and services, organization of trade and procurement procedures, related financial and logistics operations, changing consumption patterns against the background of information technology penetration and digitization of economic processes creates the basis for the formation of new markets and new conditions, as well as new approaches to analytics. forecasting and management decisions. Therefore, the purpose of the study is to study the Russian and foreign experience in the conditions of rapid development of the digital economy. Methods The study was conducted using generally accepted economic methods based on a logical description of the components and functions of digital technologies, reflecting their essential properties, using a systematic approach that provides the necessary depth of study of a scientific problem. The article reveals the current trends in the transformation of the public administration system in the context of growing global challenges to the development of digital technologies. Based on the analysis of international and Russian experience in the implementation of digital technologies and platform solutions in the field of public administration, a meaningful description of the goals and objectives of creating an "electronic government" is given. The institutional base for the formation of "e-government" and indicators that assess the level and quality of its functioning are examined.
\end{abstract}

Key words: Digital technologies, national economy, economy, public service.

В настоящее время мир переживает период активного проникновения информационных технологий (ИТ) во все сферы жизни, быстро развивается цифровая экономика и информационное общество (ИО). Современные цифровые технологии (блокчейн, технологии машинного обучения, когнитивные сервисы, системы класса СРМ / BI, умные вещи, интеллектуальные приложения для анализа больших данных и т. д.) Играют все более важную роль в корпоративном управлении отрасли мировой экономики, постепенно расширяя свое влияние и захватывая друг друга. Цифровая трансформация предполагает преобразование предприятий, организаций и сообществ в так называемые «цифровые структуры» в 


\section{ЦИФРОВИЗАЦИЯ: РОССИЯ И СНГ В КОНТЕКСТЕ ГЛОБАЛЬНОЙ ТРАНСФОРМАЦИИ}

соответствии с принципиально новыми технологическими, экономическими и социальными условиями их деятельности. [3, с. 84]

Федеральная программа «Информационное общество» (2011-2020 годы) и национальная программа «Цифровая экономика» (национальный проект), действующая в Российской Федерации, предполагают комплексное развитие инфраструктуры и технологий цифровой экономики, цифрового управления, образования, медицины, коммунальные услуги и др.

Эти программы не развиваются с нуля. Они основаны на достижениях советской науки и техники. Прежде всего, на опыте внедрения в СССР различных типов автоматизированных систем управления: автоматизированных систем управления предприятием (АСУП), отраслевых автоматизированных систем управления (ОАСУ), а также проекта Национальной автоматизированной системы управления (ОГАС). [2, с. 15]

«Стратегия развития информационного общества в Российской Федерации на 2017-2030 годы», принятая в 2017 году, и программа «Цифровая экономика в Российской Федерации» устанавливают основные принципы внедрения цифровых технологий во все сферы жизни, что требует нового формата работы органы государственной власти всех субъектов Российской Федерации. Основным вектором взаимодействия современных органов государственной власти и общества авторы видят в превращении всех государственных услуг в мобильные приложения с целью дальнейшего повышения их юзабилити для граждан субъектов Российской Федерации. Это позволит решить основную задачу применения цифровых технологий: обеспечение открытости и прозрачности современного цифрового правительства - обеспечение универсального доступа к государственным информационным услугам по принципу «любой гражданин - любое ведомство, в любое время, в любом месте», что приведет к исключение бюрократических барьеров и фактора принятия решений будет сведено к минимуму; управленческие решения будут приниматься на основе сбора данных. [4, с. 41]

Цифровизация производства позволяет предприятиям вводить принципиально иной способ организации производства, что существенно меняет процессы управления, производства и сотрудничества. Есть также новые способы взаимодействия предприятия с потребителями и 


\section{ЦИФРОВИЗАЦИЯ: РОССИЯ И СНГ В КОНТЕКСТЕ ГЛОБАЛЬНОЙ ТРАНСФОРМАЦИИ}

поставщиками, новые способы коммерциализации, новые продукты, гибкое производство. Сегодня цифровая экономика затрагивает все основные сферы: образование, здравоохранение, онлайн-банкинг, умные города, электронное правительство. Следующие отраслевые решения уже активно внедряются в субъектах Российской Федерации.

- имущественный комплекс (кадастр, права, налоги и т. д.);

- дорожно-транспортный комплекс (участки дорог, объекты инфраструктуры, объекты дорожного сервиса и т. д.);

- лесное хозяйство (налогообложение, лесные пожары, лесная патология, мероприятия и т. д.);

- сельское хозяйство (полевой мониторинг, прогнозирование урожайности, инвентаризация сельскохозяйственных земель и т. д.);

- инженерные сети (тепловые сети, электрические сети, водоснабжение, интернет, телефония и т. д.).

Однако сегодня разрыв между возможностями ИКТ в разных субъектах Российской Федерации колеблется от $3 \%$ до 65\%. Это в конечном итоге влияет на уровень жизни населения, проживающего в них. Кроме того, в России остается категория граждан, которые не имеют возможности покупать современные средства связи, учатся работать на компьютере. Поэтому они изначально находятся в неравных условиях по сравнению с другими жителями. [6, с. 25]

Реализация программы «Цифровая экономика Российской Федерации» позволит сформировать в России информационное пространство с учетом всех потребностей граждан, общества и деловых кругов. В результате реализации этой программы в Российской Федерации должна быть сформирована благоприятная правовая среда для применения технологий, повышения компетенций в этой области, развитой инфраструктуры, обеспечения киберстабильности и развития человеческого капитала. Система управления этой программой, прежде всего, ориентирована на потребности рынка, то есть бизнес формирует стратегию, формирует контент, также оценивает реализацию программы, а роль органов государственной власти заключается в утверждении решения принимаются на основании коллективного экспертного заключения. 


\section{ЦИФРОВИЗАЦИЯ: РОССИЯ И СНГ В КОНТЕКСТЕ ГЛОБАЛЬНОЙ ТРАНСФОРМАЦИИ}

В целях обеспечения охвата и прозрачности правительств субъектов Российской Федерации целесообразно: улучшить официальный сайт правительств (включая англоязычную версию), внедрить технологии онлайнвещания для заседаний правительств, комитеты и круглые столы в интернете; совершенствовать технологии размещения информации о государственной деятельности в социальных сетях.

Таким образом, основным вектором взаимодействия органов государственной власти и общества является превращение всех публичных услуг в мобильные приложения с целью дальнейшего повышения их удобства использования для граждан субъектов Российской Федерации. Необходимо создавать мобильные приложения социального характера, мобильные приложения, повышающие открытость деятельности государственных органов, разъяснения (комментарии) норм федеральных / региональных законов; новостные ленты о деятельности правительств субъектов Российской Федерации, которые будут доставлять информацию быстрее и удобнее, меняя подход к предоставлению информации в целом. Это будет отвечать главной цели применения цифровых технологий: обеспечение открытости и прозрачности современного цифрового правительства - обеспечение универсального доступа любого гражданина к информации о деятельности правительства. [3, с. 62]

Сегодня во многих странах граждане имеют право присылать свои комментарии к законопроекту в письменной форме или присылать свои предложения по электронной почте. Сбор подписей в поддержку законодательного предложения в письменной форме предусмотрен в законах Австрии, Албании, Грузии, Испании, Македонии, Польши, Румынии, Сербии, Словении, Черногории. Примечательно, что, согласно данным Национального совета Австрии, в стране с 2018 года предполагалось реализовать возможность подписания «народных инициатив» с помощью аутентичной электронной подписи. В Эстонии такая практика уже существует, в стране создан специальный портал Rahvaalgatus.ee, где граждане могут вносить предложения, участвовать в обсуждениях, собирать и отправлять коллективные электронные подписи в парламент (Riigikogu) в электронном виде через специально созданный портал. Для подачи апелляции на рассмотрение необходимо собрать не менее 1 тысячи подписей в ее поддержку. 


\section{ЦИФРОВИЗАЦИЯ: РОССИЯ И СНГ В КОНТЕКСТЕ ГЛОБАЛЬНОЙ ТРАНСФОРМАЦИИ}

Российская Федерация не предусматривает права гражданских правотворческих инициатив на федеральном уровне. В то же время законодательством ряда субъектов Федерации закреплено право граждан вносить законопроекты в законодательные органы. Тем не менее, на всех уровнях государственного управления и управления в России существует институт общественной инициативы, и любой гражданин Российской Федерации имеет право оставить свое предложение о совершенствовании государственного и муниципального управления и социально-экономического развития страны на русском языке. Инициативный портал. Если инициатива набирает необходимое количество голосов, она направляется в экспертную группу на федеральном, региональном или муниципальном уровне, которая готовит экспертное заключение и решение о разработке соответствующего нормативного правового акта и / или принимает другие меры для реализации инициативы. [2, с. 62]

Быстрые изменения, происходящие в мировой экономике, открыли важные возможности развития для малых и средних предприятий. Интернет резко сократил расходы на рекламу и продвижение, сделав их доступными не только для крупного, но и для малого и среднего бизнеса. Социальные сети стали новым каналом коммуникации с потребителем, во многих случаях более эффективным, чем традиционные СМИ.

Растущий мировой спрос на технологии Индустрии 4.0 стимулирует развитие предложения на технологических рынках, где лидерами являются компании из США, Германии и Японии. Американские компании доминируют на рынках решений для Интернета вещей (GE, Intel), его безопасности (Symantec, IBM, Intel), систем дополненной и виртуальной реальности (Facebook, AMD, Google, Microsoft). Японские компании занимают лидирующие позиции на рынках промышленных роботов и станков с ЧПУ. Немецкие компании также входят в число лидеров в ряде областей. По количеству патентов в области искусственного интеллекта лидирует Китай на его долю приходится 53\% всех патентов в этой области, США - 27\%, Япония - 6\%.

Одним из фундаментальных направлений, оказывающих влияние на промышленность и формирование концепции цифровизации в промышленности, является кластер интернет-коммерции. В 2017 году мировые продажи интернет-магазинов составили 2,5 трлн долларов (более 3\% 


\section{ЦИФРОВИЗАЦИЯ: РОССИЯ И СНГ В КОНТЕКСТЕ ГЛОБАЛЬНОЙ ТРАНСФОРМАЦИИ}

мировой экономики). В рамках ЕАЭС рынок электронной коммерции составляет 20 миллиардов долларов (1\% экономики Союза). В некоторых сегментах сектора (электроника и бытовая техника, легкая промышленность, автозапчасти, продукты питания, бытовая химия и другие товары, в основном предназначенные для конечного потребителя) интернет-коммерция уже оказывает значительное влияние.

Сегодня в России есть потенциал для развития Индустрии 4.0. Кроме того, необходимость массовой замены устаревших устройств в большинстве промышленных компаний страны позволяет немедленно начать реиндустриализацию с учетом мировых тенденций развития «Индустрии 4.0». Когда начальная фаза цифровой трансформации - «первичная оцифровка» связанные с повсеместным созданием инфраструктуры доступа в Интернет с достаточной пропускной способностью, проблемы качества использования этой инфраструктуры сейчас выходят на первый план в крупных городах на развивающихся рынках.

Помимо оцифровки, спусковым механизмом для развития малых и средних компаний стало сокращение транзакционных издержек, упрощенный доступ к международной логистике и устранение транснациональных торговых барьеров. Новым этапом развития стало появление «малых транснациональных компаний», которые активно участвуют в международной торговле со своими сотрудниками численностью до 250 человек.

Малые предприятия - производители программного обеспечения, экологически чистых продуктов питания, косметики и других производителей сейчас работают на мировом рынке. Такие инструменты, как Еbау или AliExpress, решают для них целый ряд задач по поиску клиентов, доставке, оплате и т. д. Новое поколение цифровых технологий, в основном блокчейн и смарт-контракты, в будущем позволит еще больше упростить работу малых и средних компаний на международных рынках.

В России использование таких инструментов, ориентация на экспортную ориентацию вновь создаваемых компаний может стать одним из основных источников качественного роста МСП, увеличения их участия в национальной экономике. Цифровизация экономики открывает возможности для использования новых бизнес-моделей, инструментов для структурирования бизнеса. Ключевое конкурентное преимущество - прямой 


\section{ЦИФРОВИЗАЦИЯ: РОССИЯ И СНГ В КОНТЕКСТЕ ГЛОБАЛЬНОЙ ТРАНСФОРМАЦИИ}

контакт с покупателями, более полное понимание предпочтений, факторов принятия решений, поведения потребителей.

Технологии индустриализации 4.0 открывают широкие возможности для малых предприятий по производству сложных высокотехнологичных продуктов, которые ранее были доступны только крупным корпорациям. В сочетании с подходом и механизмами D2C это значительно расширяет потенциальные рынки для МСП.

Мировой опыт показывает, что стартапы, основанные на современных бизнес-моделях и производственных технологиях, могут быть очень успешными, кроме того, что они очень привлекательны как объект инвестирования.

В последние годы в России стремительно растет экспорт программного обеспечения: среднегодовой темп роста этого показателя в 2010-2015 гг. Составил 15\%. Этому способствовало, прежде всего, стремительное развитие мирового рынка программного обеспечения. По оценкам IDC, до 2020 года в этом секторе будет наблюдаться средний рост на 7\% в год, что вдвое превышает прогнозные показатели других мировых ИТ-рынков (оборудование - 1,6\%, ИТ-инфраструктура - 5,7\%, ИТ-услуги - 3,1\%, телекоммуникационные услуги - 1,5\%) 3. Основу российского экспорта услуг по разработке программного обеспечения составляет не лицензионное ПО, а индивидуальные решения, в основном ориентированные на крупные компании. иностранцы, которые получают львиную долю прибыли от продажи конечных продуктов и услуг. К сожалению, это довольно узкая ниша на цифровом рынке, что ограничивает возможности российских разработчиков по расширению экспорта ИТ в больших масштабах.

Согласно результатам опроса, проведенного Руссофт среди российских софтверных компаний, экспорт программного обеспечения по-прежнему слабо дифференцирован географически: более 70\% его объема приходится на США, Канаду и Западную Европу. В результате, несмотря на относительно высокие темпы роста, объем экспорта программного обеспечения из России составляет всего 5-7\% от опережающего показателя Индии по этому показателю. Россия отстает от других быстрорастущих экспортеров программного обеспечения, таких как Израиль и Польша, как по объему экспорта, так и по темпам роста. Наблюдаются и негативные тенденции, выражающиеся в том, что крупные ИТ-компании переносят свои штаб- 


\section{ЦИФРОВИЗАЦИЯ: РОССИЯ И СНГ В КОНТЕКСТЕ ГЛОБАЛЬНОЙ ТРАНСФОРМАЦИИ}

квартиры в другие юрисдикции из-за желания быть ближе к рынкам продаж и партнерским рынкам, а также получить доступ к финансам и персоналу с дефицитными на рынке навыками. Русский и опыт. С другой стороны, эти компании покидают крупные центры НИОКР в России и поддерживают ИТобразование в России.

Трансляция цифровых навыков для малого и среднего бизнеса на основе опыта реализации пилотных проектов - одно из ключевых и наиболее успешных мероприятий в рамках европейских целевых программ. Такие пилотные проекты реализуются с учетом отраслевой специфики, позволяют выявить наиболее эффективные подходы к внедрению цифровых технологий в малых и средних компаниях, получить оперативную обратную связь как от компаний, так и от их клиентов.

В автомобильной отрасли реализация пилотных проектов была направлена на:

- включение малого и среднего бизнеса в цепочку поставок автопроизводителей. Основное внимание уделялось созданию соответствующей коммуникационной платформы;

- обеспечение предприятий малого и среднего бизнеса, работающих на рынке запчастей, авторизованными поставками крупных производителей.

В пилотном проекте приняли участие более 170 малых и средних испанских компаний. Были обнаружены наиболее значимые результаты: ускорение и большая прозрачность бизнес-процессов, уменьшение количества ошибок, устранение ручного ввода данных, улучшение обслуживания клиентов благодаря большей скорости и точности обработки заказов и снижению затрат на связь.

Важной тенденцией современной цифровой экономики является развитие технологий, которые позволяют малым предприятиям производить технически сложные продукты, ранее доступные только крупным, хорошо оснащенным предприятия. В частности, 3D-печать, компьютерное проектирование и моделирование могут стать локомотивом развития малого и среднего бизнеса в России. Как показывает мировая практика, важным элементом инфраструктуры поддержки малого и среднего бизнеса являются технопарки, предоставляющие своим резидентам доступ к современному 


\section{ЦИФРОВИЗАЦИЯ: РОССИЯ И СНГ В КОНТЕКСТЕ ГЛОБАЛЬНОЙ ТРАНСФОРМАЦИИ}

производственному оборудованию (многоосевые обрабатывающие центры и т. Д.).

Концепция цифрового производства представляет большой интерес для российских промышленных компаний, но реальные примеры внедрения все еще редки, а существующие носят преимущественно локальный характер изза отсутствия систематизации внедряемых решений и недостаточного понимания реализации. практика комплексных подходов в цифровом производстве. В целом автоматизация производственных участков и бизнеспроцессов в российских компаниях не имеет общих связей, а это значит, что невозможно организовать информационные коммуникации на всех уровнях производственного процесса, от проектирования и подготовки, от производства до технической поддержки. и управление материалами и распределением продукции. Этот разрыв между промышленной автоматизацией и автоматизацией ИТ ограничивает создание непрерывной информационной среды, охватывающей все уровни производственных и логистических процессов компании, необходимых для организации цифрового производства. Преодоление этого разрыва является приоритетом для цифровизации Российская промышленность.

Российские компании активно интегрируются в международные альянсы, устанавливающие технологические стандарты на долгие годы. Это позволяет синхронизировать цифровые решения, что способствует появлению ассоциаций, заинтересованных в качественно различных технологических решениях. Систематическая оцифровка всех аспектов экономики - важный шаг на пути к сознательному росту и развитию страны. Важно, чтобы компании и правительство одинаково осознавали необходимость этого этапа, сотрудничали и синхронизировали успехи.

Сегодня электронная коммерция является одним из основных драйверов роста розничной торговли. В Китае рост в прошлом году составил 52\%, а в Южной Корее 41\%. Электронная коммерция также активно растет в промышленно развитых странах: Великобритания $+8 \%$, Франция $+7 \%$, США и Япония $+5 \%$. Характерной чертой мирового розничного рынка является его высокая концентрация: на ТОП-10 компаний приходится 30\% от общего объема продаж (по данным ТОП 250), а 7 из 10 компаний - из США.

Внедрение современных технологий позволяет значительно улучшить работу предприятий по ряду направлений Industrie 4.0 может помочь 


\section{ЦИФРОВИЗАЦИЯ: РОССИЯ И СНГ В КОНТЕКСТЕ ГЛОБАЛЬНОЙ ТРАНСФОРМАЦИИ}

оптимизировать и автоматизировать ключевые производственные и управленческие бизнес-процессы, улучшить использование оборудования за счет обработки данных в реальном времени и выявления скрытых взаимозависимостей, а также улучшить планирование сырья и готовой продукции. В области обслуживания оборудования современные технологии позволяют построить систему профилактического обслуживания, работающую на основе прогнозных моделей с использованием данных в реальном времени, что помогает оценить реальную потребность в обслуживании и ремонте оборудования и оптимизировать эти процессы. Цифровизация открывает перед компаниями интересные перспективы для повышения эффективности управления складскими запасами и логистическими процессами предприятия.

В мировой практике такие конструкции уже действуют. Например, в Германии это сеть из 15 «Центров компетенции» (Kompetenzzentren) и 4 региональных офисов. Дорожная карта внедрения цифровых изменений включает 5 основных шагов 5:

1. Информация.

Что такое Индустрия 4.0? Что это может сделать для моей компании? На этом этапе сотрудники центров цифровых компетенций проводят встречи и лекции, организуют работу специалистов, конференции и семинары, анализируют возможности внедрения инноваций и т. Д. Цель этапа мотивировать руководство компании и сотрудников к внедрению цифровых изменений.

\section{2. Демонстрация.}

Как это работает на практике? Организуются визиты в компании с успешным опытом внедрения цифровых технологий нового поколения, знанием лучших практик отрасли, разработчиков технологий, компании. Цель стажировки - дать возможность оценить практический эффект от внедрения цифровых изменений.

3. Анализ и обучение.

Какие навыки необходимы компаниям и персоналу для оцифровки своего бизнеса? Проводятся тренинги, семинары, мастер-классы, консультации, «мозговые штурмы», стажировки и другие формы обучения. Цель этапа - сформировать понимание стратегии цифровизации своего 


\section{ЦИФРОВИЗАЦИЯ: РОССИЯ И СНГ В КОНТЕКСТЕ ГЛОБАЛЬНОЙ ТРАНСФОРМАЦИИ}

бизнеса, а также наиболее важных навыков и компетенций у ключевых сотрудников компании;

4. Разработка плана цифровых изменений.

Насколько компания готова к цифровизации? Какие конкретные шаги нужно предпринять? Разработка стратегии цифровизации бизнеса и плана реализации этой стратегии. Цель этапа - четкое понимание на всех уровнях компании ее целей и задач, ключевых показателей реализации стратегии цифровизации бизнеса.

\section{5. Реализация.}

На этом этапе выполняется разработанный план цифровизации, оцениваются результаты и вносятся необходимые корректировки.

Эффективное управление изменениями, необходимыми для цифровизации бизнеса, внедрение комплекса технологий «четвертой промышленной революции» - одна из основных задач формирующейся интегрированной системы развития малого и среднего бизнеса в России.

Таким образом, с ростом вовлеченности малых и средних предприятий в цифровую экономику возникает проблема информационной безопасности, защиты данных от несанкционированного использования, вирусных атак и различных вариантов кибермошенничества. возникает. Высокий уровень навыков в области корпоративной информационной безопасности, знание наиболее актуальных рисков и угроз - одна из ключевых составляющих технологического лидерства. Всесторонняя государственная поддержка в этой сфере может иметь значительный мультипликативный эффект, повышая привлекательность малых и средних предприятий в России.

Несмотря на то, что текущая макроэкономическая ситуация накладывает некоторые ограничения, существуют перспективы развития рынка рискового финансирования в России, который опирается на большой объем неиспользованного потенциала, важно ускорить темпы цифровизации и развития. Достичь к 2025 году амбициозной, но довольно реалистичной цели: утроить масштабы цифровой экономики.

\section{Список литературы}

1. Абросимова, М. А. Информационные технологии в государственном и муниципальном управлении / М.А. Абросимова. - М.: КноРус, 2013. - 248 с. 
2. Беспалов, П.В. Акмеологическая концепция формирования информационно-технологической компетентности государственных служащих / П.В. Беспалов. - М.: Каталог, 2015. - 238 с.

3. Василенко, И.А. Государственное и муниципальное управление / И.А. Василенко. - М.: Юрайт, 2014. - 416 с.

4. Василенко, И.А. Государственное и муниципальное управление. Учебник / И.А. Василенко. - М.: Юрайт, 2015. - 494 с.

5. Василенко, И.А. Государственное и муниципальное управление. Учебник: моногр. / И.А. Василенко. - М.: Юрайт, 2013. - 496 с.

6. Василенко, Л.А. Аутсорсинг - инновационная кадровая технология государственной службы / Л.А. Василенко. - М.: Наука, 2015. - 216 с. 